\title{
Educação Ambiental e Cidadania: A participação da associação do Engenho do Lixo de Juazeiro do Norte na coleta seletiva de resíduos sólidos
}

\author{
Antônio de Pádua Soares de Sampaio ${ }^{1}$; Theóphilo Michel Álvares Cabral Beserra ${ }^{2}$
}

\begin{abstract}
Resumo: O presente artigo tem por objetivo compreender o modo de vida dos catadores de materiais recicláveis que fazem parte da Associação do Engenho do Lixo de Juazeiro do Norte, bem como analisar a percepção desses em relação ao meio ambiente, através das práticas de educação ambiental. O município de Juazeiro do Norte, localizado na Região Metropolitana do Cariri, Sul do Estado do Ceará, Nordeste do Brasil, gera diariamente 250 toneladas de resíduos sólidos, que são descartados desde 2001. Espera-se que a sociedade organizada de Juazeiro do Norte, possa reconhecer legalmente os catadores, no sentido de se tornarem cidadãos de direito, com sua atividade formal reconhecida como de catadores de recicláveis.
\end{abstract}

Palavras-Chave: Catador de material reciclável; percepção ambiental; resíduos sólidos; educação ambiental.

\section{Environmental and Citizenship Education: Participation of Engenho do Lixo Association of Juazeiro do Norte in the Selective Collection of Solid Residues}

\begin{abstract}
This article aims to understand the way of life of collectors of recyclable materials that are part of the Association of Engenho do Lixo of Juazeiro do Norteand analyze the perception of these in relation to the environment, through environmental education practices. The city of Juazeiro do Norte, located in the Metropolitan Cariri Region, South of Ceara, northeastern Brazil, daily generates 250 tons of solid waste, which are dropped from 2001 in an area called Dump ofPalmeirinha, there are $6 \mathrm{~km}$ limit urban expansion area of this municipality. The intense industrialization and urbanization contribute to the generation and production of solid waste of all kinds, something around $1.00 \mathrm{~kg}$ per person / day.In order to reduce environmental impacts by large waste production, it was established in 2009the Association of Engenho do Lixo of Juazeiro do Norte to assist the population of garbage collectors in the locality. Municipal solid waste management for the development of pickers activity is the participation of the Department of Environment, Agriculture and Public Utilities - SEMASP, an agency of the City of Juazeiro do Norte. It is expected that the organized society of Juazeiro do Norte, to legally recognize the collectors, to become citizens of law, with its formal activityrecognized as waste pickers.
\end{abstract}

Keywords: Recyclable material collector; environmental awareness; solid waste; environmental education.

\footnotetext{
${ }^{1}$ Professor de Ciências - Concursado da Secretaria de Educação de Juazeiro do Norte-CE; Engenheiro Agrônomo - Concursado da Secretaria de Meio Ambiente, Agricultura e Serviços Públicos - SEMASP/JN/CE - Espec. em Resíduos Sólidos/UFRN; Pós-Graduado em Recursos Hídricos/UFC; Mestrando em Educação - ANNE SULLIVAN UNIVERITY;

2 Mestre em Geografia pela Universidade Federal do Ceará, Especialista em Geografia e Meio Ambiente pela Universidade Regional do Cariri, licenciado em geografia pela Universidade Regional do Cariri. Atualmente é membro do Conselho Municipal de Defesa do Meio Ambiente de Juazeiro do Norte - Ceará - COMDEMA, Membro do Comitê Institucional de Avaliação do Programa de Bolsas de Iniciação Científica e Tecnológica do Instituto CENTEC, Conselheiro do Eixo Tecnológico Ambiente e Saúde da Faculdade de Tecnologia CENTEC, FATEC-CARIRI, membro do Núcleo Docente Estruturante do Eixo Tecnológico Ambiente e Saúde e representante docente eleito para o Conselho de Administração do Instituto CENTEC junto a Secretaria da Ciência, Tecnologia e Educação Superior do Estado do Ceará SECITECE. Professor do eixo tecnológico ambiente e saúde. E-mail: mic.beserra@ hotmail.com.
} 
Id on Line Revista Multidisciplinar e de Psicologia

Id on Line Multidisciplinary Journal and Psycology

\section{Introdução}

A crise social ora vivenciada no Brasil tem levado muitas pessoas à sobrevivência em Juazeiro do Norte, Estado do Ceará, na catação de lixo. Nesse sentido, a Associação do Engenho do Lixo de Juazeiro do Norte, composta por homens e mulheres, tentam assegurar melhores condições de vida, através da catação de materiais reutilizáveis e recicláveis, e ao mesmo tempo, contribuir para a preservação do meio ambiente, minimizando riscos e danos a natureza.

Juazeiro do Norte teve um crescimento populacional de 37.803 habitantes na última década (IBGE/2012) devida principalmente, pelos processos de industrialização envolvendo os mais diversos sistemas de tecnologia, a urbanização e expansão da cidade com a criação de novos bairros, o aporte de universidades, o desenvolvimento do comércio, e avanços consideráveis nas áreas de engenharia e construção civil, medicina, computação e telefonia, além, da implantação de rede hoteleira de alto nível, contribuindo para alavancar o turismo na Região Metropolitana do Cariri.

Tudo isso tem contribuído na geração de emprego e renda, e consequentemente, na geração e produção de resíduos sólidos, com um total em Juazeiro do Norte, de aproximadamente 250 toneladas por dia, colocando em risco a fragilidade dos diversos ecossistemas: Parque Ecológico das Timbaúbas, Serra do Horto do Padre Cícero Romão Batista, e Rio Salgadinho ambientais. Os impactos ambientais pela deposição dos resíduos sólidos poluem os solos e água dos rios e riachos, no caso específico, do riacho dos Macacos que contribui de maneira significativa na retroalimentação do lençol freático melhorando o abastecimento d'água nas comunidades. A percepção que se tem é de uma paisagem bastante descaracterizada nesses locais da cidade.

Em suma, o presente estudo é interessante, pois mostra os fatores determinantes para as autoridades buscarem alternativas no sentido de melhorar a mobilidade entre meio de meio de as pessoas e os catadores de lixo no município de Juazeiro do Norte, diminuindo um pouco a desigualdade social, e melhorando a renda, único meio de sobrevivência, permitindo a segurança no trabalho e a possibilidade de ascender aos direitos sociais olhando para o futuro com certo otimismo. 
Id on Line Revista Multidisciplinar e de Psicologia

Id on Line Multidisciplinary Journal and Psycology

\section{Revisão de Literatura}

Segundo Oliveira (1969), lixo de uma maneira geral, é todo o resíduo sólido provenientes das atividades humanas.

Segundo Oliveira (2000), “A defesa do Ensino Fundamental como condição para a cidadania participativa, princípio ético orientador dessa luta no movimento social organizado ao longo de décadas, vem cedendo espaço aos argumentos em prol da escolaridade como meio de garantir a existência material imediata". Os catadores e catadoras da Associação Engenho do Lixo de Juazeiro do Norte deveriam ser estimulados a procurar a educação no sentido de viabilizarem sua empregabilidade.

O acumulo de lixo é um fenômeno específico das sociedades humanas, e continua sendo um dos maiores problemas ambientais da atualidade. Nosso modelo econômico atual, baseado no alto consumo de bens descartáveis, vem resultando na degradação do solo, no comprometimento dos corpos d'água e mananciais, na intensificação de enchentes, na poluição do ar, na proliferação de vetores de importância sanitária nos centros urbanos e nas condições insalubres de trabalho para os coletores desse material tanto nas ruas quanto nas áreas de disposição final. (JACOBI/2001).

Buscando aumentar a eficiência na prestação dos serviços de limpeza urbana, reduzindo a quantidade de resíduos nos aterros, gerar empego e renda e ainda movimentar o mercado da reciclagem no Brasil, devem ser articuladas parcerias com os catadores. Essas parcerias podem se dar na participação do poder público, no planejamento do trabalho, na capacitação desses profissionais, na valorização dos mesmos perante a sociedade. Essas famílias estruturadas terão condições de se organizar em associações, cooperativas visando maior produtividade e rendimento. (LIMA/2002).

Logarezzi (2004) afirma que tanto o lixo como os resíduos são sobras de uma atividade qualquer e o que as caracteriza como lixo ou resíduo depende dos valores sociais, econômicos e ambientais que atribuímos a elas, consubstanciados no ato do descarte.

Envolver efetivamente os catadores em qualquer processo de mudança é um dos aspectos que consideramos como fundamental para o alcance de qualquer melhoria em suas condições de saúde, vida e trabalho. E esse envolvimento deve ter como ponto de partida o investimento em discussões relativas à cidadania e á autoestima. Se os catadores não forem 
Id on Line Revista Multidisciplinar e de Psicoloqia

Id on Line Multidisciplinary Journal and Psycology

reconhecidos como sujeitos com direitos e deveres, bem como se não conseguirem enfrentar os estigmas que cercam a atividade de catador de materiais recicláveis, dificilmente eles se envolverão integralmente em qualquer inciativa que venha ser proposta, continuando a apontar dificuldades, sem acreditar em possíveis saídas. O cotidiano dos sujeitos que vivem da reciclagem do lixo ainda é pouco trabalhado pela saúde pública brasileira. (PORTO/2004).

A estimativa do número de catadores de materiais recicláveis no Brasil será de aproximadamente 500.000 (quinhentos mil), estando 2/3 deles no Estado de São Paulo. (MEDEIROS/2006).

Com a crescente globalização a desigualdade social torna-se cada vez maior, podemos observar que as pessoas que não possuem estudo e acesso aos serviços e bens de consumo são condenadas a viverem à margem da sociedade onde são impulsionadas cada vez mais para a exclusão social. A coleta de materiais recicláveis torna-se uma alternativa comum para estas pessoas; uma possibilidade de sobrevivência. O trabalho de catação de lixo quando não é a principal, torna-se uma forma complementar de geração de renda e reprodução destes grupos familiares. (SILVA et al. 2007).

Rios (2008) citando Legaspe (1998), “O trabalho do catador assenta-se em grande parte na exploração de uma massa de trabalhadores miseráveis que são obrigados, pelos mais diferentes instrumentos coercitivos, econômicos e sociais, a buscar o trabalho realizado com o lixo, formas de sobrevivência".

A Política Nacional dos Resíduos Sólidos - PNRS regula os planos municipais de gestão integrada de resíduos sólidos, contemplando desde a geração até sua disposição final, após todos os esforços de reutilização e reciclagem terem sido empregados. Dessa forma, ciclo indústria consumidor cooperativa/associação de catadores intermediário (quando houver) indústria é completo, maximizando a utilização da matéria-prima e minimizando a geração de resíduos. Nesse modelo, os catadores, ou trabalhadores nos serviços de coleta de resíduos, ocupação regulamentada pelo Ministério do Trabalho e Emprego, exercem, portanto, um papel fundamental. (BRASIL/2010).

O Brasil gera, diariamente, mais de 200 mil toneladas de resíduos sólidos de origem industrial e domiciliar. (ABRELPE/2013).

Segundo a Secretaria de Meio Ambiente, Agricultura e Serviços Públicos de Juazeiro do Norte - SEMASP, a Associação do Engenho do Lixo de Juazeiro do Norte, recolhe em 
Id on Line Revista Multidisciplinar e de Psicoloqia

Id on Line Multidisciplinary Journal and Psycology

média, 40 (quarenta) toneladas de materiais recicláveis por mês nas principais ruas do Centro de Juazeiro do Norte, com a participação de 7 (sete) catadores. (SEMASP/2015).

\section{Criação da Associação do Engenho do Lixo ee Juazeiro do Norte.}

A Associação do Engenho do Lixo de Juazeiro do Norte, Estado do Ceará foi criada em 9 de agosto de 2009, na sede da Secretaria de Meio Ambiente e Serviços Públicos de Juazeiro do Norte, sendo o Sr. Francisco Alvino escolhido o seu primeiro presidente, de acordo com a primeira ata. Com base na Lei $N^{\circ} 3755$ de 13 de outubro de 2010, do Poder Executivo - Gabinete do Prefeito Municipal de Juazeiro do Norte - Dr. Manoel Raimundo de Santana Neto, publicada no Diário Oficial do Município - Caderno I do dia 15 de outubro de 2010 - Ano XIII, N ${ }^{\circ}$ 2881, Autoriza o chefe do Poder Executivo Municipal a firmar instrumento de doação com cláusula resolutiva em favor da Associação do Engenho do Lixo de Juazeiro do Norte, pessoa jurídica de direito privado, sem fins lucrativos, inscrita no CNPJ/MF $\mathrm{N}^{\mathrm{o}}$ 11.263.979/0001-07, constituindo de parte da gleba 02, objeto de matrícula $\mathrm{N}^{\mathrm{o}}$ 1.295 do Livro $N^{\circ} 2$ do Cartório Machado - $2^{\circ}$ Oficio - Juazeiro do Norte, essa área de terra de $4.000 \mathrm{~m}^{2}$, avaliado para fins do artigo 101 da Lei Orgânica do Município de Juazeiro do Norte, em R\$ 384.000,00, conforme Laudo de Avaliação $\mathrm{N}^{\mathrm{o}}$ 0002/2010. Portanto, a Associação do Engenho do Lixo de Juazeiro do Norte, fica estabelecida neste município, com endereço a Avenida Paulo Maia, Nº 230, bairro Santo Antônio.

\section{Metodologia}

O presente estudo técnico constou de uma pesquisa-levantamento, aonde as entrevistas e consultas foram realizadas na própria sede da Associação do Engenho do Lixo de Juazeiro do Norte, situada a Avenida Paulo Maia, no 230, bairro Santo Antônio, Juazeiro do Norte, estado do Ceará.

As observações de natureza qualitativa e quantitativa, com a população de catadores e catadoras de materiais recicláveis e reutilizáveis (resíduos sólidos), todos componentes da 
Id on Line Revista Multidisciplinar e de Psicologia

Id on Line Multidisciplinary Journal and Psycology

Associação do Engenho do Lixo de Juazeiro do Norte, que contava na época do estudo com 10 (dez) catadores de ambos os sexos. No total, foram identificados 7 catadores e 3 catadoras.

A pesquisa para a coleta de dados tratava de questões básicas sobre a coleta de resíduos sólidos potencialmente recicláveis, envolvendo também, a identificação do catador, seu nível de escolaridade, sua estrutura (composição) familiar, seu histórico em participação na coleta seletiva de resíduos sólidos, sua remuneração mensal, sua saúde, além, de sua percepção de vida como catador de lixo e preservação do meio ambiente.

Houve acompanhamento da operação de coleta nos bairros centrais da cidade de Juazeiro do Norte.

A entrevista foi muito importante para saber como se sentem em relação as suas condições de vida, suas perspectivas dentro da Associação Engenho do lixo de Juazeiro do Norte como a renda, a saúde, a desigualdade social e de classes, sua visão diferentemente da visão do gari de coleta regular de resíduos sólidos domiciliares, compreendendo os catadores, que os mesmos fazem parte de mão de obra sem qualificações técnicas para a realização da coleta seletiva. A falta de estrutura na cadeia da reciclagem no município de Juazeiro do Norte, desde a gestão pública e privada, contribui para a informalidade do setor.

Os dados obtidos foram registrados pelo próprio autor do estudo, com a aceitação plena de todos os catadores de materiais recicláveis e reutilizáveis, membros efetivos da Associação do Engenho do Lixo de Juazeiro do Norte, que na ocasião se apresentaram favoráveis a participar da pesquisa-levantamento com o consentimento do seu presidente, o Sr. Antônio Jerônimo da Silva.

\section{Resultados e Discussão}

A pesquisa-levantamento apresentou como resultado os seguintes dados: a predominância numa proporção de $70 \%$ é de indivíduos do sexo masculino, e um total de 10 pessoas, todos os membros da Associação Engenho do Lixo de Juazeiro do Norte. média de idade dos componentes é de 52 anos, com pessoas já numa idade avançada, sem perspectiva de conseguir trabalho formal, mas apresentando condições para assumir a catação de materiais recicláveis garantindo a sua subsistência. 
Id on Line Revista Multidisciplinar e de Psicoloqia

Id on Line Multidisciplinary Journal and Psycology

Quanto à raça, predomina o negro com quase $90 \%$, e o restante, 10\%, branco/pardo. Quanto ao Estado Civil, em torno de $50 \%$ é casado(a), a outra metade é desquitado(a). Segundo Kaloustian/2000, citado por Rios/2008, “A família é o espaço indispensável para garantir a sobrevivência de desenvolvimento e da proteção integral dos filhos, e demais membros, independentemente de arranjo familiar ou da forma como vem se estruturando. Ela desempenha um papel decisivo na educação formal e informal”.

Os catadores entrevistados possuem mais de quatro filhos, sem qualquer controle de natalidade, prole excessiva para os dias atuais.

Quanto ao grau de escolaridade, $80 \%$ apresenta saber ler e escrever, com a maioria, em torno de $90 \%$ não concluiu o Ensino Fundamental. Os resultados evidenciam o baixo nível de escolaridade dos catadores e catadoras da Associação do Engenho do Lixo de Juazeiro do Norte, contribuindo para a não inserção dos mesmos no mercado de trabalho formal, cada vez mais exigente em formação e qualificação técnica. Segundo Oliveira/2000, "A melhoria da educação promove o crescimento do capital humano e do capital social de um país. O capital social é um indicador do quanto ganhamos ao viver em uma sociedade em decorrência da qualidade das pessoas e das instituições com as quais interagimos...”. Os catadores deveriam ser beneficiados através de políticas públicas com programas consistentes, com a oferta de projetos alternativos de educação profissional, em busca de maior escolaridade, com competências para a aquisição de empregos, requalificação, condizente aos novos padrões tecnológicos.

Dos entrevistados, $70 \%$ (sete catadores) atuam como catador a aproximadamente 5 anos. No que comprova, a função de catador é uma atividade recente na cidade de Juazeiro do Norte.

A metade dos entrevistados afirma ter retorno financeiro para sustentar sua família, com a grande maioria, em torno de $80 \%$ obtendo um faturamento líquido mensal de mais de um salário mínimo.

O estudo revela que $80 \%$ dos catadores não possui casa própria. A grande maioria mora de favor, com parentes próximos, em barracos ou pequenas casas alugadas.

Todos os catadores (100\%) se consideram trabalhadores autônomos sendo catadores de materiais recicláveis, e o mais interessante, fizeram essa opção, no sentido de preservar o meio ambiente. 
Id on Line Revista Multidisciplinar e de Psicologia

Id on Line Multidisciplinary Journal and Psycology

A carga horária diária dos catadores é em média de 8 horas (de 7:00 ás 15:00 horas).

Os principais materiais recicláveis coletados são: Alumínio - 10\%, Cobre $-5 \%$, Sucata (Ferro) - 10\%, Antimônio - 5\%, Eletrônico - 10\%, Plástico duro - 20\%, Plástico mole $-5 \%$, PET $-10 \%$, e Papelão - 25\%. Todos esses materiais são armazenados no prédio da Associação Engenho do Lixo de Juazeiro do Norte.

A Prefeitura Municipal de Juazeiro do Norte, através da Secretaria de Meio Ambiente, Agricultura e Serviços Públicos - SEMASP, fornece ajuda aos catadores, com o aluguel de um caminhão marca Mercedes-Benz, carroceria de madeira, com capacidade $-5 \mathrm{~m}^{3}$, para a realização da coleta seletiva de resíduos sólidos.

Todos os catadores fazem uso de EPI'S. A maioria já se acidentou na catação, através de materiais perfuro-cortante, lâminas, etc., que atingiram os braços e pernas, chegando a comprometer a saúde dos mesmos. Quando isso ocorre, os mesmos procuraram ajuda na UPA 24 Horas - Unidade de Pronto Atendimento e no Hospital Regional do Cariri - HRC, ambos localizados na cidade de Juazeiro do Norte. No atendimento, foram vacinados: contra o tétano e contra a gripe, e fizeram solicitação para a realização de vários exames: sangue, urina, e fezes.

Quase todos os catadores faz uso de tabaco (cigarro comum, cigarro de fumo forte, etc.), e de álcool (cachaça), piorando a saúde e comprometendo a qualidade no trabalho, e dificultando a sua integração social e o relacionamento entre as pessoas,

Dos entrevistados na Associação do Engenho do Lixo de Juazeiro do Norte, todos afirmam vender o material reciclável coletado para alguns atravessadores, de maior potencial financeiro e pelas vantagens que esse sistema oferece as indústrias de reciclagem de resíduos sólidos.

Os catadores de recicláveis da Associação Engenho do Lixo de Juazeiro do Norte, devido à exclusão social e a discriminação, conforme resultado na entrevista estruturada aplicada aos mesmos, no dia 19 de Janeiro de 2016, as 09h00min afirmaram em potencial, serem mal vistos pela prefeitura e pela população de Juazeiro do Norte, não conseguindo escapar da pobreza, devido à falta de educação, baixa escolaridade, exclusão social, e se achando impossível sair dessa grave situação. Todos os catadores afirmaram enfrentar dificuldades, além de sofrerem humilhações, desprezo, preconceitos e racismo, por parte da população em geral. 
As relações sociais entre os catadores percebe-se claramente a desestruturação familiar, aonde os pais não se dedicam aos filhos, devido ter de trabalhar praticamente o dia todo fora de casa, no sentido de se obter renda satisfatória para a sobrevivência de todos.

A falta de uma educação ambiental de qualidade e participativa, por parte dos gestores públicos e privados de Juazeiro do Norte, fazem com que as pessoas continuem a jogar lixo nas ruas, nas praças e monumentos, se tornando poluidores em potencial, sem conscientização ambiental.

\section{Considerações Finais}

Através desse estudo de campo bem detalhado, foi possível alcançar o objetivo principal, no caso, o estudo detalhado do perfil dos catadores e catadoras de resíduos sólidos com potencial para a reciclagem da Associação Engenho do Lixo de Juazeiro do Norte, analisando também, a percepção do catador em relação à preservação do meio ambiente e os principais aspectos sociais envolvidos na atividade.

As pessoas envolvidas nesse processo devem ser incluídas socialmente, devido à quase total inexistência de capacitação técnica, a falta de estudos (baixa escolaridade), a baixa perspectiva de vida pela insalubridade do ambiente, a dificuldade de acesso aos serviços básicos de saúde e a falta muitas vezes de bens de consumo necessário à própria sobrevivência, como alimentos e roupas. A grande maioria dos catadores está estabelecida na periferia da cidade de Juazeiro do Norte, morando em barracos, a margem da sociedade e excluída.

A baixa remuneração sobre a venda dos materiais recicláveis contribui para um trabalho exaustivo, mas, no que em muito ajudaria os catadores no processo de mudança no município com relação aos resíduos sólidos. Essa deve ser a busca permanente de todos focando no trabalho e nos benefícios econômico, social e ambiental advindo do processo da reciclagem. O trabalho dos associados vai angariar benefícios econômicos, sociais e ambientais, com a coleta e venda de materiais recicláveis, mantendo a coleta seletiva nos bairros e preservando o meio ambiente. 
Os conflitos gerados na sociedade de Juazeiro do Norte, em geral, tem piorado a distribuição de renda, diminuindo o número de empregos formais, no as pessoas desqualificadas e excluídas, necessitam sobreviver e buscam um trabalho informal, no caso em estudo, os membros que compõem a Associação do Engenho do Lixo de Juazeiro do Norte.

Toda essa população carente necessita e apoio da gestão pública, no que a Secretaria de Meio Ambiente, Agricultura e Serviços Públicos - SEMASP da Prefeitura Municipal de Juazeiro do Norte vem desenvolvendo práticas de educação ambiental, despertando uma consciência ambiental nos catadores para resolver a problemática dos resíduos sólidos, e ao mesmo tempo, aumentando a renda familiar de todos. (SEMASP/2015).

\section{Referências}

ABRELPE. Associação Brasileira de Empresas de Limpeza Pública e Resíduos Especiais. Panorama dos resíduos sólidos no Brasil. São Paulo: ABRELPE, 2013.

BRASIL. Lei $\mathrm{n}^{\circ}$ 12.305, de 02 de agosto de 2010. Politica Nacional de Resíduos Sólidos. Diário Oficial da União, Brasília, 2010.

IBGE. Instituto Brasileiro de Geografia e Estatística. Projeção da população brasileira. Brasília - DF em 15 de fevereiro de 2016. http://www.ibge.gov.br/home/.

JACOBI, P. R.; Besen, G. R. Solid waste management in São Paulo: the challenges of sustainability. Estudos Avançados, v. 25, n. 71, p. 135 - 158, 2001.

LIMA, José Dantas. Gestão de resíduos sólidos urbanos no Brasil. Associação Brasileira de Engenharia Sanitária e Ambiental - ABES, Seção Paraíba, João Pessoa, 2002, P.247.

LOGAREZZI, A. Contribuições conceituais para gerenciamento de resíduos sólidos e ações de educação ambiental. In: LEAL, A. C. Resíduos sólidos no Pontal de Paranapanema. Presidente Prudente - SP, Ed. Antônio Thomaz Junior, 2004. P. 276.

MEDEIROS, L.F.R.; Macedo, K.B. Catador de material reciclável: uma profissão para além da sobrevivência? Psicologia \& Sociedade, 18(2), 62-71, 2006.

OLIVEIRA, Dalila Andrade. Educação Básica: Gestão do Trabalho e da Pobreza. Petrópolis, Rio de Janeiro, Editora Vozes, 2000, P.360. 
OLIVEIRA, W. E. Saneamento do lixo. In: UNIVERSIDADE DE SÃO PAULO. Faculdade de Higiene e saúde Pública. Lixo e Limpeza Pública. São Paulo: USP/OMS/OPS, 1969. P. 11.

PORTO, Marcelo Firpo de Souza; Denise Chrysóstomo de Moura Juncá; Raquel de Souza Gonçalves e Maria Izabel de Freitas Filhote. Lixo, trabalho e saúde: um estudo e caso com catadores em um aterro metropolitano no Rio de Janeiro, Brasil. Caderno Saúde Pública, Rio de Janeiro, 20(6): 1503-1514, novembro-dezembro, 2004.

RIOS, Cristiane Margarete. Lixo e Cidadania: Um Estudo sobre Catadores de Recicláveis em Divinópolis - MG, Fundação Educacional de Divinópolis - Universidade Estadual de Minas Gerais, Divinópolis, 2008.

SEMASP. Secretaria de Meio Ambiente, Agricultura e Serviços Públicos de Juazeiro do Norte. Relatório de Limpeza Pública. Juazeiro do Norte, Ceará, Dezembro de 2015.

SILVA, D.B.; Lima, S.C. Catadores de Materiais Recicláveis em Uberlândia MG, Brasil: Estudo e Recenseamento. Revista Caminhos da Geografia. Uberlândia, Junho, 2007.

Como citar este artigo (Formato ABNT):

SAMPAIO, A.P.S.; BESERRA, T.M.A.C. Educação Ambiental e Cidadania: A participação da associação do Engenho do Lixo de Juazeiro do Norte na coleta seletiva de resíduos sólidos. Id on Line Revista Multidisciplinar e de Psicologia, Out-Nov. de 2016, vol.10, n.31, Supl 3, p. 45-55. ISSN 1981-1179.

Recebido: $14 / 09 / 2016$

Aceito: $24 / 10 / 2016$ 